\title{
Research on Novel Training Pattern for National Training Plan based on Promoting Professional Ability and Deepening Theoretical Approach
}

\author{
Lijun Wang ${ }^{1}$ \\ ${ }^{1}$ Hubei University of Science and Technology, \\ Xianning City, Hubei Province,437100 China
}

\author{
Danxia Liu ${ }^{1, *}$ \\ ${ }^{1}$ Hubei University of Science and Technology, \\ Xianning City, Hubei Province,437100 China \\ * Corresponding Author
}

\begin{abstract}
In this paper, we research on novel training pattern for national training plan based on promoting professional ability and deepening theoretical approach. Under the changing social situation and the education of the development of the situation, the country's education policy is to continuously put forward new standards and requirements of teachers, primary and secondary school teachers in-service take part in the various content of continuing education training. Our proposed novel pattern will enhance the performance of the traditional national training plan which will be meaningful and necessary. In the future research, we will conduct more related research.
\end{abstract}

Keywords: National Training Plan; Professional Ability; Deepening Theoretical; New Methodology.

\section{Introduction}

The cultivation plan of primary and secondary school teachers training not only promotes the development of training teachers' personal, eventually trained teachers will apply the training results in the education teaching, use in the classroom, the student and its ultimate aim is to cultivate can effectively implement the quality education of teachers in practice, teachers play the real functions. Field work can make the students will learn theoretical knowledge into the daily practice, is engaged in the teaching activities of the students are in the process of continuous learning, constantly improve their practice ability. On the other hand, through the practice of reflection and try, will further improve the level of students' theoretical knowledge, generate new is different from the understanding of the textbooks teaching materials. The cultivation plan of project implementation is the ministry of education and ministry of finance, national compulsory education stage teacher training project, is by far the highest level of primary and secondary school teachers training projects, its coverage involved in the central and western regions in our country, influence range and degree of deep, very tall to the requirement of training resources. The project the importance of culture and investment is very large. In this case, how to make this huge investment gain enough income, maximize the project training benefits, is worth us to explore problems [1]. Training to obtain the biggest benefit, we must ensure the quality of training to achieve the best. Therefore, the analysis of the factors influencing the quality of training has become we consider important premise and foundation of training benefits.

The changing social situation and the education of the development of the situation, the country's education policy is to continuously put forward new standards and requirements of teachers, primary and secondary school teachers in-service take part in the various content of continuing education training, to improve their comprehensive qualities, the expansion of new teaching idea [2]. The traditional teacher training model, are in training institutions, and cultivating 
teachers as times, training institutions in the active status and culture teachers in a passive position to hold the refs. The performance of the teaching methodology could be easily organized as the following sections. (1) Education training plan and scheme. The success of a training activity, the first training solution depends on the scientific nature and rationality, scientific rationality of scheme is to ensure that the activity is an important prerequisite for successful implementation. (2) Education training objectives. Clear feasible teacher training target is one of the key factors to ensure the quality of training. (3) Education and training policies. The reality is that both at home and abroad, if not forcing, teachers consciously to attend training very hard, especially domestic, because the realistic problems, such as establishment and graduation rates pressure is not willing to sacrifice the normal work of the school time for teachers' participation in training. This involves the policy support issues. (4) Education training mode. According to different target of training, the choice of different groups of different content, different training model is to create one of the key factors for effective training. These four patterns are researchers according to actual sums up the typical type of teacher training, they have their own scope of application, adjust measures to local conditions according to the specific situation and the establishment of appropriate choice of the mode of training is the key to ensure the training quality [3]. (5) Trainers. Is another key factor affecting the quality of training teachers according to the characteristics and required a targeted select teachers training is one of the important factors to ensure the quality of training. Relative to a specific training program, must fully consider the above various factors affecting the quality of teacher training each other between science as a whole [4].

In this paper, we research on novel training pattern for national training plan based on promoting professional ability and deepening theoretical approach. Social and cultural theory is that the social environment and personal factors work together to promote the learning activities. Social environment through its agents, such as culture, language and social institutions such as things affect people's cognitive development. The language is the important tools of individuals modify their behavior and thinking. Social and cultural theory and mutual conversation between learners through collective, consciously take on new tasks. Teacher development causes model for this study provides an efficient analysis function and it reflects the teacher development environment of dynamic connection between main causes which will be discussed in detail in the next sections.

\section{The Proposed Novel Training Pattern}

The Traditional National Training Plan. Countries culture projects as the ministry of education, ministry of finance jointly launched a national training project on may affect all aspects of training effect, the ministry of education and the provincial education department has a relatively clear rules and requirements, especially in such aspects as training goals and objectives, policy support is no problem. But in training plan and plan, training content and form, training mode, trainees and trainers are larger operational space. The following will be taken from all the above factors affecting the quality of training staff to "countries culture plan" project on the benefit of the training related parties may produce is analyzed, in order to find out the methods and way to maximize the benefits.

No matter what kind of training program and in all training benefit related parties, trainees are realizing the objective of the project undertaker directly, therefore, the trainee's own training benefit is the basis and core of all training programs benefit "countries culture plan" project, of course, no exception. So, how to make students in the process of training to achieve the best effect of training, so that "countries culture plan" project upon students realize the maximization of the benefit will be project 
achieve the ultimate goal and achieve the maximum benefit of priority. Through the program to train a group of "seed" teachers, to make them in advancing quality education and teacher training plays a backbone role model. Development of teacher training of high quality resources, innovation of teacher training mode and method, promote the national large-scale primary and secondary school teachers training carried out. Support the mid-west rural teacher training, guide and encourage local perfect teacher training system, strengthen the rural teacher training, improve the quality of teachers in rural. Promote the reform of teacher education, and promote higher normal colleges and universities for basic education, basic education services. Countries culture includes model training programs for primary and secondary school teachers, the Midwest rural backbone teachers' training program two content, indicates that the nation's emphasis on teachers team construction.

But the author through a large number of literatures also found the cultivation plan for a long time or some problems more or less. (1) Research hollow, floating. Most of the host country culture units before the start of the project plan will usually send the student questionnaire, but the reality is often the results of the questionnaire citing "all tastes are ignored, basically have no effect on the expert's training content. (2) Training content exist the phenomenon of "old wine in new bottles". (3) Training evaluation which becomes a mere formality. The cultivation plan should be arranged in a timely manner to the training content, teaching, management, service conditions, such as the student satisfaction situation investigation. Therefore, the reform of the traditional method is needed.

The Promoting Professional Ability Approached. Strengthen the teacher training, is to further implement the scientific concept of development, promote the education fair is an important measure, is deep the implementation of quality education, inevitable requirement to improve the quality of education in an all-round way, and the broad masses of the inner needs and desires of teacher professional development. The pre-school education is an important part of national education system, is an important social public welfare undertakings. Do before the academic education and the relationship between the healthy growth of hundreds of millions of children and the vital interests of the dry home thousands of households, the future of the relationship between the state and nation. In recent years, the government increased the support for preschool education, but overall, preschool education is still the weak link in the education of all types and at all levels. Along with the deepening of education reform, in improving the quality of training, focusing on the training objects at the same time, people are paying attention to trainees. Years of managerial experience tells us that the concept of trainers directly affects the training courses design determine the overall effect of training. The present is called after the curriculum reform era. The following figure shows the method.

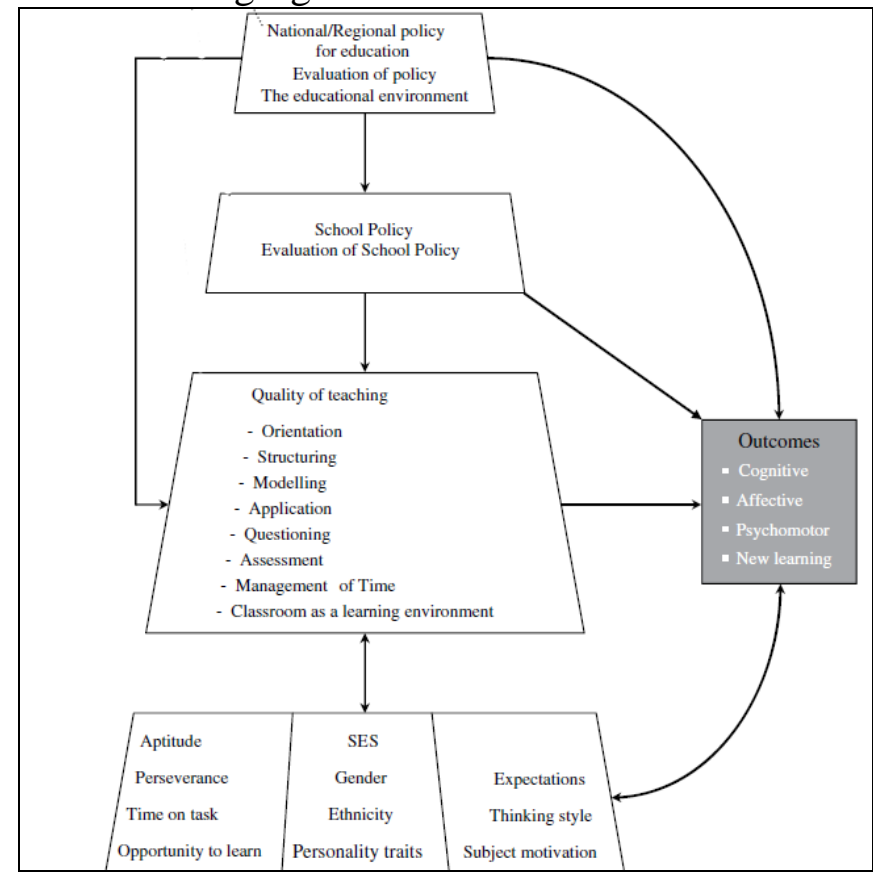

Figure 1. The Novel Pattern of Promoting Professional Ability 
Previous research from theory to build the culture plan basic system, focusing on the research the training plan implementation process. But on the mutual relationship between the elements of architecture culture plan inherent attributes and elements of research is less. In fact in the process of project implementation, including macro and micro training two big aspects. Macro level, the real requirements through research training trainers, from training needs guidance training objectives, training content selected by the training objectives, training content binding training methods.

The Deepening Theoretical Methods. Curriculum system construction should not only based on macro society needs, the region's education and school development needs, but also based on the responsibility of training object and qualifications, as well as the training objects growth law and education development strategy target put forward new requirements to the training object. Especially to investigation and analysis, based on the requirement of training object and focus on discipline development, actively absorb the forefront research results. Training target is expected end. According to training needs analysis, training institutions set a target to comprehensive consideration of three levels of training objectives, namely national goals based on macro society needs, based on the trained teachers in education needs, to the development of the school district and school goals, based on the personal goals of training object itself. Learning needs and resources assessment is an important principle of adult learning. Before the start of the training, organizers should adopt a variety of channels to get in touch with the student, is student's basic situation, students training form desired, such as content for research. Lecture focused training is the most direct way. Not only time focus, training, and the amount of information is relatively abundant, impart knowledge of higher efficiency. However, in actual teaching process, this way is easy to cramming education problems, the lack of interaction. Students often feel boring and don't understand which don't want to hear. For students, they are very eager to forms of interactive communication, whether the discussion between students, or the communication between with trainers.

The Prospect and Additional Suggestions. The evaluation of learning resources is one of the important links that not allow to be ignored. We need to keep thinking: how in the limited funds, pooling available resources, build a benign, training resources for the sustainable development of the network; How do you maintain training teachers of long-term and stable cooperation; How to provide the most suitable for students learning, living conditions, including classroom, teaching facilities, books and materials, computer room, multimedia, etc. Also note that the student group itself is also a great resource, but the resources, often neglected in the training. Training can provide a platform to arrange some communication BBS theme. Only under a clear purpose could we design a suitable curriculum. This requires training course designer to deeply understand the meaning of culture, from the social level, organization level, subject level and individual level to deeply analyze. Aimed at cultivating students demand high level, not only capable of learning has strong expansibility and mobility demand characteristics, designed to help students form of style of teaching and education advocated targeted general course of practice.

\section{Conclusion}

In this paper, we research on novel training pattern for national training plan based on promoting professional ability and deepening theoretical approach. Curriculum system construction should not only based on macro society needs, the region's education and school development needs, but also based on the responsibility of training object and qualifications. The cultivation plan of project implementation is the ministry of education and 
ministry of finance, national compulsory education stage teacher training project, is by far the highest level of primary and secondary school teachers training projects. We firmly believe that through the proposed approach, we could obtain better result and gain more precious knowledge in the national training plan.

\section{Acknowledgement}

This paper is supported by the scientific research projects of Hubei University of science and technology (NO. KY14017). The supporting project name is: enhancing the primary and secondary school English teachers' training quality analysis and the methodology.

\section{References}

[1] She-hui D, University G M. The National Legal Personnel Training Plan and the Talent Demand of Ethnic Minority Areas-Talking about the training of excellence legal talents for ethnic minority.

[2] Kunxiang Z. Research on Standardized Management of the "National Training Plan" Program[J]. Journal of Qujing Normal University, 2014.

[3] Jun F, Hong Z, Mathematics C O, et al. After Training Evaluation Model Research for National Training Mathematics Teachers[J]. Journal of Tonghua Normal University, 2014.

[4] Xuejuan Y, University L C. The Analysis of Gansu Province Rural Schools Sports Teachers' Training Needs in National Training Program $[\mathrm{J}]$. Guide of Science \& Education, 2014. 